\title{
Perbedaan Kebersihan Rongga Mulut dan Kesehatan Periodontal Antara Mahasiswa Kedokteran Gigi dengan Mahasiswa Kesehatan Non-Kedokteran Gigi di Universitas Jember
}

(The Differences of Oral Hygiene and Periodontal Health Between Dental Students with Non-Dental Health Students in Jember University)

\section{Sita Amelia', Depi Praharani², Dyah Setyorini ${ }^{3}$}

1 Pendidikan Kedokteran Gigi, Fakultas Kedokteran Gigi, Universitas Jember

2 Bagian Periodonsia, Fakultas Kedokteran Gigi, Universitas Jember

3 Bagian Pedodonsia, Fakultas Kedokteran Gigi, Universitas Jember

\begin{abstract}
Abstrak
Kesehatan gigi dan mulut merupakan bagian penting dari kesehatan tubuh secara umum dan terkait dengan beberapa faktor. Faktor domain perilaku merupakan salah satu faktor yang terkait yang terdiri dari pengetahuan, sikap, dan tindakan. Tujuan penelitian ini adalah untuk menganalisis perbedaan oral hygiene dan kesehatan periodontal pada mahasiswa kedokteran gigi dengan mahasiswa non kesehatan gigi Universitas Jember. Penelitian ini merupakan penelitian observasional analitik cross-sectional. Subyek penelitian adalah 274 mahasiswa kesehatan Universitas Jember. Data diperoleh dengan cara pengambilan kuesioner dan pemeriksaan klinis menggunakan OHIS untuk mengetahui status oral hygiene dan CPITN untuk memeriksa status kesehatan periodontal. Hasil penelitian ini adalah mahasiswa kedokteran gigi dan mahasiswa non kesehatan gigi memiliki tingkat kebersihan mulut yang sama yaitu tingkat sedang dengan skor OHI-S mahasiswa kedokteran gigi lebih rendah dibandingkan mahasiswa non kesehatan gigi. Kesimpulan dari penelitian ini adalah tidak terdapat perbedaan status kesehatan periodontal mahasiswa kedokteran gigi dengan mahasiswa non kesehatan gigi Universitas Jember.
\end{abstract}

Kata kunci: CPITN, mahasiswa kedokteran gigi, mahasiswa non kesehatan gigi, OHI-S

\section{Abstract}

Oral health is an important part of general body health and is related by several factors, behavioral domain factor is one of related factor consisting of knowledge, attitudes, and actions. The purpose of this study is to analyze the differences of oral hygiene and periodontal health in dental students with non-dental health students at Jember University. This research was an observational analytic with cross-sectional findings. The subjects were 274 Jember University health students. Data obtained by taking questionnaires and clinical examinations using OHI-S to determine the oral hygiene status and CPITN to examine the periodontal health status. The result of this study is dental students and non-dental health students has the same level of oral hygiene that is the medium level with lower OHI-S scores for dental students compared to non-dental health students. The conclusion of this study is there is no difference in the periodontal health status of dental students with non-dental health students at Jember University.

Keywords: CPITN, dental students, non-dental health students, OHI-S

Korespondensi (Correspondence) : Sita Amelia. Pendidikan Kedokteran Gigi, Fakultas Kedokteran Gigi, Universitas Jember. Jl. Tegalboto No.37 Jember. Email: sitaamelia@ymail.com

Kesehatan gigi dan mulut merupakan salah satu bagian dari kesehatan jasmani yang tidak dapat dipisahkan satu dengan yang lainnya karena jika dipisahkan akan mempengaruhi kondisi tubuh secara keseluruhan. ' Kebersihan gigi dan mulut merupakan salah satu hal yang penting dalam menjaga keseimbangan fungsi tubuh, kebersihan rongga mulut juga merupakan salah satu faktor penentu kesehatan gigi dan mulut.2 Hasil Riset Kesehatan Dasar (RISKESDAS) mengenai prevalensi permasalahan gigi dan mulut di Indonesia pada tahun 2007 sebesar 23,4\%, pada RISKESDAS tahun 2013 sebesar $25,9 \%$, dan pada RISKESDAS tahun 2018 mencapai angka $57,6 \%$ yang berarti terjadi peningkatan prevalensi permasalahan gigi dan mulut setiap tahunnya di Indonesia.3.,45 WHO melaporkan bahwa salah satu penyakit gigi dan mulut yang banyak dijumpai di masyarakat adalah penyakit periodontal. Hasil penelitian Nazir tahun 2017 mendapatkan $86 \%$ dari populasi yang diteliti di Indonesia menderita penyakit periodontal dan hanya $14 \%$ yang tidak menderita penyakit periodontal. 6

Penyakit periodontal adalah penyakit inflamasi yang terjadi pada jaringan pendukung gigi yaitu gingiva, ligamen periodontal, sementum, dan tulang alveolar. Jika penyakit ini tidak dirawat maka akan menyebabkan kehilangan perlekatan dan kerusakan progresif jaringan periodontal sehingga terjadi tanggal gigi.? Penyebab utama penyakit periodontal adalah bakteri plak yang merupakan kumpulan mikroorganisme atau bakteri yang berkembang biak, terikat dalam suatu matriks organik, dan melekat erat pada permukaan keras gigi. ${ }^{8}$

Permasalahan gigi dan mulut dipengaruhi oleh faktor domain perilaku kesehatan yang terdiri dari pengetahuan, sikap dan tindakan. Pengetahuan yang diperoleh atau dimiliki seseorang dapat menentukan sikap dan tindakan seseorang terhadap kesehatannya. 9 Pada penelitian yang dilakukan oleh Rahtyanti (2017) kepada mahasiswa baru Fakultas Kedokteran Gigi Universitas Jember tahun akademik 2016/2017 
mengenai pengaruh pengetahuan tentang kesehatan gigi dan mulut terhadap tingkat karies gigi didapatkan hasil bahwa semakin rendah tingkat pengetahuan kesehatan gigi dan mulut maka tingkat karies akan semakin tinggi. 10

Mahasiswa kedokteran gigi dan mahasiswa kesehatan non-kedokteran gigi sama-sama memiliki pengetahuan mengenai kesehatan yang didapatkan dari pendidikan sesuai dengan bidang kesehatan masingmasing. Tujuan dari penelitian ini adalah untuk menganalisis perbedaan tingkat kebersihan rongga mulut dan status kesehatan periodontal mahasiswa kedokteran gigi dan mahasiswa kesehatan non-kedokteran gigi di Universitas Jember.

\section{METODE PENELITIAN}

Penelitian ini merupakan penelitian analitik observasional dengan pendekatan cross sectional dan mendapatkan izin dari Komisi Etik Penelitian Kesehatan (KEPK) Fakultas Kedokteran Gigi Universitas Jember No.214/UN25.8/KEPK/DL/2018. Penelitian dilakukan pada bulan Maret-Mei 2019 di Klinik Periodonsia Rumah Sakit Gigi dan Mulut Universitas Jember dengan jumlah sampel yang diteliti sebanyak 274 mahasiswa kesehatan Universitas Jember dengan menggunakan metode purposive sampling. Kriteria sampel pada penelitian ini yaitu sampel bersedia menjadi responden dengan menandatangani informed consent, tidak menggunakan alat orthodontik lepasan atau cekat, tidak menggunakan gigi tiruan sebagian lepasan atau cekat, tidak sedang mengkonsumsi obat-obatan diantaranya fenitoin; kontrasepsi oral; karbamazepin; ciclosporin; calcium-channel blocker (nifedipin, verapamil, diltiazem, sodium valproat); dan immunosupresan, tidak memiliki kelainan sistemik seperti diabetes mellitus; kelainan darah; peyakit jantung; hipertensi; asma; malnutrisi; dan epilepsi, tidak sedang menstruasi, tidak sedang hamil, atau memakasi alat kontrasepsi. Tidak menggunakan oral jewelry, tidak memiliki kebiasaan buruk seperti merokok dan menginang.

Sebelum melaksanakan penelitian subyek di instruksikan untuk menyikat gigi dan tidak makan sebelum dilakukan pemeriksaan kebersihan rongga mulut dan kesehatan periodontal, dan dilakukan prosedur persetujuan dengan pengisian inform consent. Pengumpulan data diperoleh melalui kuesioner, pemeriksaan status kebersihan rongga mulut dan kesehatan periodontal. Subjek diminta untuk mengisi informed consent terlebih dahulu, kemudian subjek menjawab pertanyaan kuesioner secara langsung dan dilakukan pemeriksaan kondisi kebersihan rongga mulut menggunakan Oral Hygiene Index simplified (OHI-S) serta pemeriksaan kesehatan periodontal menggunakan Community
Periodontal Index of Treatment Needs (CPITN). Kesehatan periodontal adalah keadaan yang menggambarkan kondisi dari jaringan periodontal yang diukur menggunakan CPITN. ${ }^{11}$

Data dari hasil penelitian tersebut diolah untuk dilakukan uji normalitas menggunakan uji Kolmogrov Smirnov dan uji homogenitas menggunakan uji Levene untuk mengetahui distribusi data. Selanjutnya dilakukan uji perbedaan untuk mengetahui perbedaan tingkat kebersihan rongga mulut dan status kesehatan periodontal antara mahasiswa kedokteran gigi dengan mahasiswa kesehatan non kedokteran gigi, jika data berdistribusi normal dan homogen maka uji perbedaan menggunakan uji one way annova sedangkan jika data tidak bersitribusi normal dan tidak homogen maka uji perbedaan menggunakan uji Kruskal Wallis. Uji LSD dilakukan jika terdapat perbedaan saat melakukan uji one way anova untuk mengetahui signifikansi perbedaan antar kelompok. Hasil disajikan dalam bentuk tabel distribusi frekuensi.

\section{HASIL PENELITIAN}

Hasil pemeriksaan kebersihan rongga mulut dengan $\mathrm{OHI}$-S menunjukan rata-rata skor OHI-S berturut-turut dari yang paling rendah yaitu mahasiswa Fakultas Kedokteran Gigi (FKG), mahasiswa Fakultas Kesehatan Masyarakat (FKM), mahasiswa Fakultas Keperawatan (FKEP), mahasiswa Fakultas Kedokteran (FK), dan mahasiswa Fakultas Farmasi (FF). Meskipun demikian rata-rata skor OHI-S mahasiswa kelima fakultas tersebut termasuk dalam tingkat kebersihan mulut yang sama yaitu sedang tabel 1. Hasil pemeriksaan kesehatan periodontal dengan CPITN menunjukkan bahwa mahasiswa kelima fakultas tersebut sebagian besar mempunyai skor CPI 2 dan tidak satupun mahasiswa dari kelima fakultas tersebut mendapatkan skor CPI 4.

Kebutuhan perawatan (TN) berdasarkan hasil pemeriksaan kesehatan periodontal dengan CPITN menunjukkan bahwa mahasiswa kelima fakultas tersebut sebagian besar membutuhkan perawatan TN 2 yaitu instruksi kebersihan mulut dan professional scaling, tidak satupun mahasiswa dari kelima fakultas tersebut membutuhkan TN 3 tabel 2. Pada hasil kuesioner sebagian besar baik mahasiswa kedokteran gigi maupun mahasiswa kesehatan non-kedokteran gigi sudah memiliki pengetahuan yang baik mengenai pemeliharaan kebersihan dan kesehatan gigi dan mulut walaupun masih terdapat mahasiswa kedokteran gigi dan mahasiswa kesehatan non-kedokteran gigi yang memiliki pengetahuan keliru mengenai hal tersebut tabel 3.

Hasil analisa uji perbedaan skor $\mathrm{OHI}-\mathrm{S}$ menggunakan uji one way anova menunjukkan bahwa nilai signifikansi 0,000 $(p<0,05)$ yang berarti terdapat perbedaan 
skor OHI-S antara mahasiswa kedokteran gigi dengan mahasiswa kesehatan nonkedokteran gigi. Uji lanjutan LSD dilakukan untuk mengetahui perbedaan skor $\mathrm{OHI}-\mathrm{S}$ antar kelompok. Hasil uji LSD didapatkan nilai $\mathrm{p}<0,05$ yang berarti skor OHI-S antar kelompok terdapat perbedaan yang signifikan kecuali antara FK dengan FF, FK dengan FKM, FK dengan FKEP, FF dengan FKEP, dan FKM dengan FKEP. Hasil uji perbedaan skor CPI menggunakan uji Kruskal Wallis yaitu hasil $p>0,05$ yang berarti tidak terdapat perbedaan skor CPI antar kelompok yang signifikan.

\section{PEMBAHASAN}

Kebersihan rongga mulut merupakan salah satu acuan untuk menentukan kesehatan rongga mulut. Kesehatan gigi dan mulut tidak hanya mengenai gigi, tetapi juga berhubungan dengan gusi, tulang pendukung, dan jaringan lunak pada mulut, lidah dan bibir. Skor OHI-S mahasiswa kedokteran gigi lebih rendah dibandingkan dengan skor OHI-S mahasiswa kesehatan nonkedokteran gigi. Meskipun demikian tingkat kebersihan mulut mahasiswa kedokteran gigi maupun mahasiswa kesehatan nonkedokteran gigi termasuk dalam kategori yang sama yaitu sedang. Hasil tersebut kemungkinan karena terdapat perbedaan perilaku menjaga kesehatan gigi dan mulut antara mahasiswa kedokteran gigi dengan mahasiswa kesehatan non-kedokteran gigi. Kesehatan rongga mulut dapat dipengaruhi oleh faktor domain perilaku yang terdiri dari pengetahuan, sikap, dan tindakan dalam menjaga dan membersihkan gigi dan mulut, perilaku kesehatan yang baik dapat mewujudkan kebersihan mulut yang baik.10 Pengetahuan subyek tentang kesehatan gigi dan mulut termasuk didalamnya mengenai cara pemeliharaan kebersihan dan kesehatan gigi dan mulut dapat dilihat pada hasil kuesioner yang telah diisi oleh subyek.

Hasil penelitian menunjukkan bahwa sebagian besar mahasiswa kesehatan nonkedokteran gigi sudah pernah mendapatkan penyuluhan seputar kesehatan gigi dan mulut, tetapi pada hasil pemeriksaan kebersihan gigi dan mulut menunjukkan terdapat perbedaan skor OHI-S antara mahasiswa kedokteran gigi dengan mahasiswa kesehatan non-kedokteran gigi. Hasil ini mungkin karena pengetahuan yang dimiliki mahasiswa kesehatan non-kedokteran gigi tidak diikuti dengan sikap dan tindakan yang baik. Pernyataan tersebut dapat didukung oleh hasil kuesioner bahwa sebagian besar mahasiswa kesehatan nonkedokteran gigi walaupun sudah pernah mendapat penyuluhan seputar kesehatan gigi dan mulut masih memiliki pemahaman yang keliru mengenai plak gigi dan frekuensi kontrol ke dokter gigi. Sebagian besar mahasiswa kesehatan non-kedokteran gigi ternyata memiliki pemahaman bahwa plak merupakan lapisan keras yang terdiri dari bakteri dan sisa makanan, bahkan masih terdapat mahasiswa kesehatan nonkedokteran gigi yang tidak mengetahui definisi dari plak. Plak sebenarnya adalah deposit lunak berupa lapisan tipis yang melekat pada permukaan gigi yang terdiri atas akumulasi atau kumpulan debris sisa makanan, bakteri, dan produk-produknya. Plak yang menumpuk apabila dibiarkan akan mengalami kalsifikasi dan akan membentuk kalkulus yang melekat erat pada permukaan gigi. Komponen-komponen tersebut merupakan salah satu tanda yang dapat menentukan kebersihan rongga mulut sehingga pemahaman yang keliru dapat mempengaruhi cara pemeliharaan kebersihan gigi dan mulut menjadi kurang baik atau optimal.8,12

Tabel 1. Rata-rata skor OHI-S pada mahasiswa kedokteran gigi dan mahasiswa kesehatan nonkedokteran gigi

\begin{tabular}{lccc}
\hline \multicolumn{1}{c}{ Fakultas } & Jumlah (n) & Rata-rata OHI-S & Tingkat Kebersihan Mulut \\
\hline Kedokteran Gigi (FKG) & 47 & 1,58 & Sedang \\
Kedokteran (FK) & 41 & 2,76 & Sedang \\
Farmasi (FF) & 51 & 2,81 & Sedang \\
Kesehatan Masyarakat (FKM) & 63 & 2,41 & Sedang \\
Keperawatan (FKEP) & 72 & 2,70 & Sedang \\
\hline Total & $\mathbf{2 7 4}$ & $\mathbf{2 , 4 7}$ & Sedang \\
\hline
\end{tabular}

Tabel 2. Distribusi frekuensi TN berdasarkan skor CPI pada mahasiswa kedokteran gigi dan mahasiswa kesehatan non-kedokteran gigi.

\begin{tabular}{|c|c|c|c|c|c|c|c|c|c|c|c|}
\hline \multirow{3}{*}{\multicolumn{2}{|c|}{ CPITN }} & \multicolumn{10}{|c|}{ Fakultas } \\
\hline & & \multicolumn{2}{|c|}{ FKG } & \multicolumn{2}{|c|}{ FK } & \multicolumn{2}{|c|}{$\mathrm{FF}$} & \multicolumn{2}{|c|}{ FKM } & \multicolumn{2}{|c|}{ FKEP } \\
\hline & & $\mathbf{N}$ & $\%$ & $\mathbf{N}$ & $\%$ & $\mathbf{N}$ & $\%$ & $n$ & $\%$ & $n$ & $\%$ \\
\hline 0 & 0 & 0 & 0 & 1 & $2,4 \%$ & 0 & 0 & 0 & 0 & 0 & 0 \\
\hline 1 & I & 1 & $2,1 \%$ & 0 & 0 & 0 & 0 & 2 & $3,2 \%$ & 3 & 4,2 \\
\hline $\begin{array}{l}2 \\
3\end{array}$ & ॥ & 46 & $97,9 \%$ & 40 & $97,6 \%$ & 51 & $100 \%$ & 61 & $96,8 \%$ & 69 & 95,8 \\
\hline 4 & III & 0 & 0 & 0 & 0 & 0 & 0 & 0 & 0 & 0 & 0 \\
\hline \multicolumn{2}{|c|}{ Total } & 47 & 100 & 41 & 100 & 51 & 100 & 63 & 100 & 72 & 100 \\
\hline
\end{tabular}

N, jumlah; \%, prosentase 
Tabel 3. Data Hasil Kuesioner

\begin{tabular}{|c|c|c|c|}
\hline Pertanyaan & Jawaban & $\begin{array}{c}\text { Mahasiswa } \\
\text { Kedokteran Gigi }\end{array}$ & $\begin{array}{c}\text { Mahasiswa } \\
\text { Kesehatan } \\
\text { Non-kedokteran } \\
\text { Gigi }\end{array}$ \\
\hline $\begin{array}{l}\text { Pernah mendapat } \\
\text { penyuluhan seputar } \\
\text { KESGILUT }\end{array}$ & $\begin{array}{l}\text { Sekali } \\
\text { Beberapa kali } \\
\text { Tidak pernah }\end{array}$ & $\begin{array}{c}4,26 \% \\
95,74 \% \\
0 \%\end{array}$ & $\begin{array}{l}28,63 \% \\
48,46 \% \\
22,91 \%\end{array}$ \\
\hline $\begin{array}{l}\text { Frekuensi menyikat } \\
\text { gigi dalam sehari }\end{array}$ & $\begin{array}{l}\text { Tiga kali } \\
\text { Dua kali } \\
\text { Satu kali }\end{array}$ & $\begin{array}{c}27,66 \% \\
72,34 \% \\
0 \%\end{array}$ & $\begin{array}{c}22,47 \% \\
74,89 \% \\
2,64 \% \\
\end{array}$ \\
\hline $\begin{array}{l}\text { Waktu yang benar } \\
\text { saat menyikat gigi }\end{array}$ & $\begin{array}{l}\text { Setelah mandi pagi dan sore } \\
\text { Sarapan pagi dan sebelum tidur } \\
\text { Ketika kotor }\end{array}$ & $\begin{array}{c}4,26 \% \\
95,74 \% \\
0 \%\end{array}$ & $\begin{array}{c}22,47 \% \\
76,21 \% \\
1,32 \%\end{array}$ \\
\hline $\begin{array}{l}\text { Permukaan yang } \\
\text { dibersihkan saat } \\
\text { sikat gigi }\end{array}$ & $\begin{array}{l}\text { Permukaan luar dan dalam } \\
\text { Permukaan luar, dalam dan lidah } \\
\text { Permukaan luar }\end{array}$ & $\begin{array}{l}12,77 \% \\
78,72 \% \\
8,51 \% \\
\end{array}$ & $\begin{array}{c}55,07 \% \\
43,61 \% \\
1,32 \% \\
\end{array}$ \\
\hline $\begin{array}{l}\text { Waktu mengganti } \\
\text { sikat gigi }\end{array}$ & $\begin{array}{l}>6 \text { bulan sekali } \\
3-6 \text { bulan sekali } \\
\text { saat rusak }\end{array}$ & $\begin{array}{c}0 \% \\
82,98 \% \\
17,02 \%\end{array}$ & $\begin{array}{l}3,96 \% \\
78,41 \% \\
17,62 \%\end{array}$ \\
\hline Fungsi menyikat gigi & $\begin{array}{l}\text { Menghilangkan karang gigi } \\
\text { Menghilangkan sisa makanan } \\
\text { Membuat gigi menjadi putih }\end{array}$ & $\begin{array}{c}2,13 \% \\
93,62 \% \\
4,26 \% \\
\end{array}$ & $\begin{array}{c}8,81 \% \\
88,55 \% \\
2,64 \% \\
\end{array}$ \\
\hline $\begin{array}{l}\text { Pentingnya } \\
\text { menjaga } \\
\text { kebersihan mulut }\end{array}$ & $\begin{array}{l}\text { Penting, menjaga penampilan } \\
\text { Penting, permasalahan tubuh lain } \\
\text { Tidak penting }\end{array}$ & $\begin{array}{l}0 \% \\
100 \% \\
0 \% \\
\end{array}$ & $\begin{array}{c}4,41 \% \\
95,59 \% \\
0 \%\end{array}$ \\
\hline $\begin{array}{l}\text { Hal yang } \\
\text { menyebabkan } \\
\text { permasalahan gigi } \\
\text { dan mulut }\end{array}$ & $\begin{array}{l}\text { Merokok } \\
\text { Mengkonsumsi makanan manis tapi } \\
\text { kurang dalam menyikat gigi } \\
\text { Makanan bebas gula }\end{array}$ & $\begin{array}{l}8,51 \% \\
91,49 \% \\
0 \%\end{array}$ & $\begin{array}{l}11,45 \% \\
86,78 \% \\
1,76 \%\end{array}$ \\
\hline $\begin{array}{l}\text { Apa yang diketahui } \\
\text { tentang plak gigi }\end{array}$ & $\begin{array}{l}\text { Lapisan keras yang berisi bakteri } \\
\text { dan sisa makanan } \\
\text { Lapisan lunak yang berisi bakteri } \\
\text { dan sisa makanan } \\
\text { Tidak tahu }\end{array}$ & $\begin{array}{l}21,28 \% \\
78,72 \% \\
0 \%\end{array}$ & $\begin{array}{l}85,46 \% \\
12,33 \% \\
2,20 \%\end{array}$ \\
\hline $\begin{array}{l}\text { Frekuensi kontrol ke } \\
\text { dokter gigi }\end{array}$ & $\begin{array}{l}\text { Sesuai anjuran saja } \\
\text { 2-3 kali/tahun } \\
\text { Tidak sama sekali }\end{array}$ & $\begin{array}{l}23,40 \% \\
46,81 \% \\
29,79 \%\end{array}$ & $\begin{array}{l}8,37 \% \\
15,86 \% \\
75,77 \%\end{array}$ \\
\hline
\end{tabular}

Mahasiswa kesehatan non-kedokteran gigi juga sebagian besar sama sekali tidak melakukan kontrol ke dokter gigi. Rata-rata rutinitas perawatan diri di rumah berlangsung kurang dari 2 menit dan hanya menghilangkan $40 \%$ biofilm plak, sehingga harus tetap melakukan kontrol ke dokter gigi secara rutin agar tercapai kebersihan serta kesehatan gigi dan mulut yang baik. ${ }^{7}$ Hasil penelitian ini sejalan dengan hasil penelitian dari Nurjannah tahun 2016 yang mendapatkan bahwa tidak ada hubungan yang bermakna antara pengetahuan terhadap status kebersihan gigi dan mulut pada pelajar SMP/MTs Pondok Pesantren Putri Ummul Mukminin Makasar. ${ }^{13} \mathrm{Hal}$ ini menunjukkan bahwa tingkat pengetahuan subyek yang baik tidak selalu diikuti dengan status kebersihan gigi dan mulut yang baik pula

Pemeriksaan CPITN mendapatkan hasil bahwa tidak terdapat perbedaan status kesehatan periodontal antara mahasiswa kedokteran gigi dengan mahasiswa kesehatan non-kedokteran gigi. Sebagian besar mahasiswa kesehatan Universitas Jember baik mahasiswa kedokteran gigi maupun mahasiswa kesehatan nonkedokteran gigi mendapatkan skor CPI 2 yaitu terdapat kalkulus supra atau subgingiva atau timbunan plak di sekeliling margin gingiva dan tidak terdapat poket lebih dari $3 \mathrm{~mm}$. Hal ini kemungkinan dikarenakan masih terdapat perilaku yang kurang tepat atau kurang optimal pada mahasiswa keseharan baik kedokteran gigi maupun non-kedokteran gigi dalam menjaga kesehatan gigi dan mulut yang dapat meningkatkan akumulasi plak dan pembentukan kalkulus. Hasil kuesioner menunjukkan 21,28\% mahasiswa kedokteran gigi menjawab bahwa plak adalah lapisan keras yang terdiri dari bakteri dan sisa makanan. Padahal plak adalah lapisan lunak yang terdiri dari bakteri dan debris sisa makanan dan merupakan etiologi primer dari penyakit periodontal. ${ }^{8}$ Hasil kuesioner juga menunjukkan 4,26\% mahasiswa kedokteran gigi menyikat gigi dengan waktu yang tidak tepat yaitu setelah mandi pagi dan sore hari. Waktu yang tepat untuk menyikat gigi adalah saat pagi hari setelah sarapan dan malam hari sebelum tidur sehingga dapat membersihkan sisa-sisa makanan yang menempel setelah makan pagi dan setelah 
makan malam. ${ }^{14}$ Malam hari selama tidur aliran saliva menurun dan efek protektif saliva menjadi hilang, berkurangnya sekresi saliva dapat mengurangi kemampuan self cleaning rongga mulut dan akan meningkatkan pembentukan plak. ${ }^{15}$ Berdasarkan hasil kuesioner didapatkan $8,51 \%$ mahasiswa kedokteran gigi menyikat gigi hanya pada permukaan luar gigi saja. Cara menyikat gigi yang baik adalah dengan membersihkan seluruh bagian gigi mulai dari permukaan gigi bagian dalam, luar dan bagian pengunyahan. ${ }^{16}$ Pembersihan lidah juga sangatlah penting karena permukaan dorsum lidah adalah tempat utama bagi pertumbuhan mikroorganisme, khususnya bakteri anaerob. Tindakan pembersihan lidah selain dapat meningkatkan tampilan klinis, juga dapat mengeliminasi sebagian bakteri fakultatif anaerob dan obligat anaerob yang berperan dalam penyakit periodontal. ${ }^{17}$ $17,02 \%$ mahasiswa kedokteran gigi dari hasil kuesioner diketahui mengganti sikat gigi hanya pada saat sikat gigi rusak. Sikat gigi yang sudah berusia 3 bulan atau bulu sikat sudah mekar dan rusak seharusnya diganti dengan sikat gigi yang baru agar pembersihan gigi menjadi optimal. ${ }^{18}$ Cara pemeliharaan sikat gigi juga dapat cara menentukan kebersihan mulut yang tidak benar sehingga menyebabkan mudahnya akumulasi bakteri plak yang merupakan faktor etiologi utama penyakit periodontal. ${ }^{19}$

Pada $29,79 \%$ mahasiswa kedokteran gigi dari hasil kuesioner masih didapatkan yang tidak sama sekali melakukan kontrol ke dokter gigi. Kontrol ke dokter gigi dilakukan sebagai perawatan pemeliharaan yang bertujuan untuk mempertahankan kesehatan rongga mulut dan mencegah kekambuhan penyakit gigi dan mulut.7 Kebutuhan perawatan yang dibutuhkan berdasarkan hasil penelitian ini baik pada mahasiswa kedokteran gigi maupun mahasiswa kesehatan nonkedokteran gigi adalah instruksi kebersihan mulut, kebutuhan perawatan scaling dan root planing. Scaling adalah proses menghilangkan plak dan kalkulus dari permukaan gigi supragingiva dan subgingiva. Root planing adalah proses di mana sisa kalkulus yang tertanam di bagian sementum dihilangkan untuk menghasilkan permukaan yang halus dan bersih. Tujuan utama scaling dan root planing adalah untuk memulihkan kesehatan gingiva dengan sepenuhnya menghilangkan elemen yang memicu peradangan gingiva dari permukaan gigi. Setelah dilakukan perawatan scaling penting untuk dilakukan pemberian edukasi cara menjaga kebersihan mulut yang baik dan benar agar tetap terjaga kesehatan rongga mulut? ${ }^{7}$

Disimpulkan bahwa tingkat kebersihan rongga mulut mahasiswa kedokteran gigi dengan mahasiswa kesehatan non-kedokteran gigi di Universitas Jember termasuk dalam kategori sedang. Status kebersihan rongga mulut mahasiswa kedokteran gigi lebih rendah dibandingkan dengan mahasiswa kesehatan non-kedokteran gigi. Tidak terdapat perbedaan status kesehatan periodontal mahasiswa kedokteran gigi dengan mahasiswa kesehatan non-kedokteran gigi di Universitas Jember.

Berdasarkan hasil penelitian ini perlunya peningkatan kesadaran perilaku menjaga kesehatan gigi dan mulut yang lebih baik lagi untuk mahasiswa kedokteran gigi maupun mahasiswa kesehatan non-kedokteran gigi di Universitas Jember agar dapat menjadi contoh yang baik bagi masyarakat luas, serta perlunya dilakukan perawatan scaling dan root planing yang diikuti dengan pemberian instruksi kebersihan mulut. Berdasarkan penelitian yang telah dilakukan, maka saran yang dapat diberikan yaitu perlu dilakukan penelitian lebih lanjut untuk memperoleh status kebersihan rongga mulut dan kesehatan jaringan periodontal pada seluruh mahasiswa di Universitas Jember.

\section{DAFTAR PUSTAKA}

1. Wowor V, Lossu FM, Pangemanan DHC. Hubungan Pengetahuan Kesehatan Gigi Dan Mulut Dengan Indeks Gingiva Siswa Sd Katolik 03. J e-Gigi. 2015;3(2):647-53.

2. Hadnyanawati $\mathrm{H}$. View of PERILAKU MENJAGA KESEHATAN GIGI DAN MULUT PADA SANTRI PONDOK PESANTREN ALAZHAR JEMBER. Stomatognatic (J. K. G Unej) Vol. 10 No. 1. Published 2013. Accessed August 28, 2021. https://jurnal.unej.ac.id/index.php/STOM A/article/view/2016/1624

3. Badan Penelitian dan Pengembangan Kesehatan. Laporan Nasional Riskesdas 2007. Lap Nas 2007. Published online 2007:1-384.

http://kesga.kemkes.go.id/images/pedo man/Riskesdas 2007 Nasional.pdf

4. R. Riset Kesehatan Dasar. Kementeri Kesehat Rl. Published online 2013. doi:10.1517/13543784.7.5.803

5. Riskesdas. Hasil Utama Riset Kesehatan Dasar. Kementrian Kesehat Republik Indones. Published online 2018:1-100. doi:1 Desember 2013

6. Nazir MA. Prevalence of periodontal disease, its association with systemic diseases and prevention. Int J Heal Sci Vol 1, Issue 2, April. 2017;1(2):72. doi:10.1 109/ISIP.2008.139

7. MICHAEL G. NEWMAN, DDS, FACD and FERMIN A. CARRANZA, DR ODONT F. Newman and Carranza's Clinical Periodontology 13th Ed.; 2019.

8. Ladytama RS, Nurhapsari A, Baehaqi M. EFEKTIVITAS LARUTAN EKSTRAK JERUK NIPIS (Citrus Aurantifolia) SEBAGAI OBAT KUMUR TERHADAP PENURUNAN INDEKS 
PLAK PADA REMAJA USIA 12-15 TAHUN Studi di SMP Nurul Islami, Mijen, Semarang. ODONTO Dent J. 2014;1 (1):39. doi:10.30659/odj.1.1.39-43

9. Agusta $R$ MV, $A K$ Al, Firdausy MD. Hubungan pengetahuan kesehatan gigi dengan kondisi. Mendali J. 2014;2(1):648.

10. Rahtyanti GCS, Hadnyanawati H, Wulandari E. Hubungan Pengetahuan Kesehatan Gigi dan Mulut dengan Karies Gigi pada Mahasiswa Baru Fakultas Kedokteran Gigi Universitas Jember Tahun Akademik 2016/2017. Pustaka Kesehat. 2018;6(1):167.

11. Ermawati T, Sari DS, Aris M, Kundari W. Status kesehatan periodontal dan tingkat kebutuhan perawatan pasien yang datang ke klinik periodonsia rsgm universitas jember tahun 2011. JKG Unej. 2012;9(2):86-9.

12. Basuni, Cholil, Putri DKT. Gambaran Indeks Kebersihan Mulut Berdasarkan Tingkat Pendidikan Masyarakat di Desa Guntung Ujung Kabupaten Banjar. Dentino J Kedokt Gigi. 2014;II(1):18-23.

13. Nurjannah. Hubungan Pengetahuan, Sikap dan Tindakan Kesehatan Gigi dan Mulut terhadap Kebersihan Mulut Pelajar SMP/MTs Pondok Pesantren Putri Ummul Mukminin. J Dent. Published online 2016:1-102.
14. Sufriani RA. Gambaran Menggosok Gigi Dan Kebiasaan Mengkonsumsi Makanan Kariogenik Pada Anak Usia Sekolah Di Sdn 54 Tahija Banda Aceh. J Syiah Kuala Dent Soc. 2018;1 (3):37-43.

15. Triswari D, Dian Pertiwi A. Pengaruh Kebiasaan Menyikat Gigi Sebelum Tidur Malam Terhadap Skor Indeks Plak dan pH Saliva. Insisiva Dent J Maj Kedokt Gigi Insisiva. 2017;6(2):1-8.

16. Setiari LS, Sulistyowati M. Tindakan Pencegahan Karies Gigi Pada Siswa Sekolah Dasar Berdasarkan Teori Health Belief Model. J PROMKES. 2018;5(1):65. doi:10.20473/jpk.v5.i1.2017.65-76

17. Hamid H, Aulia R, Samad R. Efektivitas penggunaan tongue scraper terhadap penurunan indeks tongue coating dan jumlah koloni bakteri anaerob lidah. Dentofasial. $2011 ; 10$ (1):32-5.

18. Widyastuti RN. Pengaruh Media BukU Bergambar SOGl (Menggosok Gigi ) Terhadap Pengetahuan dan Praktik Menggosok Gigi Pada Siswa Madrasah Ibtidaiyah Negeri Sumurejo Kecamatan Gunungpati Semarang Tahun 2015. Skripsi $\backslash$. Published online 2015:30.

19. Praharani D, Pujiastuti P, Ermawati T. Status kebersihan mulut dan kesehatan periodontal pasien yang datang ke Klinik Periodonsia RSGM Universitas Jember Periode Agustus 2009 - Agustus 2010. J Stogmatognatic. $2011 ; 8(3): 163-9$ 